\title{
Impact assessment of climatic and land-use changes on flood runoff in southeast Queensland
}

\author{
Yi-Ru Chen \& Bofu Yu \\ School of Engineering, Griffith University, Gold Coast, Australia \\ Yi-ru.chen@griffith.edu.au
}

\begin{abstract}
Over the past century land-use change has increased rapidly in southeast Queensland, and when coupled with climatic change the risk of flooding increases. This research aims to examine impacts of climate and land-use changes on flood runoff in southeast Queensland, Australia. A rainfall-runoff model, RORB, was calibrated and validated using observed flood hydrographs for one rural and one urbanised catchment, for 1961-1990. The validated model was then used to generate flood hydrographs using projected rainfall based on two climate models, Geophysical Fluid Dynamics Laboratory Climate Model 2.1 (GFDL CM2.1) and Conformal-Cubic Atmospheric Model (CCAM), for 2016-2045. Projected daily rainfall for the two contrasting periods were used to derive adjustment factors for a given frequency of occurrence. Two land-use change scenarios were used to evaluate likely impacts. Based on the projected rainfall, results showed that future flood magnitudes are unlikely to increase for large flood events for both catchments. Extreme land-use change would significantly impact flooding in the rural catchment, but not the urbanised catchment.
\end{abstract}

Key words climate change; land-use change; floods; RORB; CCAM; GFDL CM2; Queensland, Australia

\section{INTRODUCTION}

Worldwide, flooding is a common environmental hazard, and also one of the major natural hazards that can cause death and considerable economic losses. For example, in both 2011 and 2012, summer floods led to the evacuation of many people from their homes in southeast Queensland (SEQ), Australia. Projected rapid land-use changes, when coupled with climate change, could potentially lead to increased flood risks with deleterious impact on infrastructure (Ewen \& Parkin, 1996; Poelmans et al. 2011). However, the precise effects of such changes are difficult to predict, because average recurrence intervals for some flood events may increase or decrease (Leander et al., 2008).

General circulation models (GCMs) and regional climate models (RCM) have become popular tools to assess the impacts of climate change on hydrological behaviour (Chiew \& McMahon 2002; Booij 2005; Charles et al. 2007). Kay et al. (2006) used outputs from a RCM and a hydrologic model to simulate current and future flood frequency in the UK, with input data from 1961-1990 and 2071-2100. Interestingly, the model-projected results show a decreased flood frequency in the future across the UK, especially in south-eastern catchments. However, the observed data in the last decade show there is a noteworthy increase of floods in south-eastern catchments which is different from their analytical results. Kay et al. (2009) argued that sources of uncertainty in estimating future flood frequency could emanate from the emission scenarios, GCMs and RCMs or hydrological models used to produce flood hydrographs. They found that the GCMs are the main source of uncertainty in estimating future flood frequency.

A few assessments of GCMs skill have been carried out in Australia (Charles et al. 2007; Perkins et al. 2007). Charles et al. (2007) applied the CCAM with three other GCMs to western Australia and evaluated the bias from these climatic models over two periods, viz. 1975-2004 and 2035-2064. They found that CCAM produce the best results over the four climatic models compared with the annual precipitation from the observation. The Geophysical Fluid Dynamics Laboratory Climate Model 2.1 (GFDL CM2.1) and the Conformal-Cubic Atmospheric Model (CCAM) have been extensively studied, and their 
outputs have been validated through comparison with observations ( Delworth et al., 2006; Gnanadesikan et al., 2006; Nguyen \& McGregor, 2009; Das et al., 2011; Chen et al., 2012; Gooda \& Voogt, 2012; Kent et al., 2012; Nguyen \& McGregor, 2012). Chen et al. (2012) used outputs from GFDL CM2.1 and CCAM to assess changes to floods in southeast Queensland (SEQ). They firstly validated the GCMs projected rainfall by comparing with observed rainfall, and found that GFDL CM2.1 projected rainfall was consistent with observations. Based on the GFDL CM2.1 projected rainfall, no significant changes to floods in SEQ was found in their study (Chen et al., 2012). Kent et al. (2012) compared outputs from 12 downscaled models with observations and found that CCAM downscaled from the MK3.0 produced the best predictions in annual and seasonal rainfalls out of 12 models. The quality in terms of spatial distribution of CCAM predicted rainfall was much higher when compared with other GCM predicted rainfall (Nguyen \& McGregor, 2012). Nevertheless, each climate model has its own strengths, and users should be careful when using outputs from climate models for hydrological studies.

GCM outputs and hydrological models are commonly used in the literature to evaluate future flood risk without considering land-use change. The influence of only land-use change on surface runoff has been investigated in many studies (Chow et al., 1988; Lahmer et al., 2001; Tollan, 2002; Bathurst et al., 2004; Bathurst et al. 2011a, Bathurst et al. 2011b). Lahmer et al. (2001) stated that the development of land-use scenarios is a complex task, and they demonstrated how to develop land-use scenarios in their study. The first step is to decide the type of model and the spatial scale, and then to test the sensitivity limits of the model with an extreme land-use change. To create land-use scenarios, Lahmer et al. (2001) also stated that an extreme change and a realistic scenario should be included in the developed scenarios.

Sriwongsitanon and Taesombat (2011) argued that the effect of land-use change on flood behaviour is likely to occur for moderate storms, but this effect is reduced during extreme rainfall events. Poelmans et al. (2011) used three land-use scenarios to assess changes in flood peaks in a small catchment in Belgium. Findings from Poelmans et al. (2011) agreed with statements of Sriwongsitanon and Taesombat (2011). Only a few studies have considered a combination of climate and land-use change scenarios for flood impact assessment (Chang \& Franczyk, 2008; Ouellet et al., 2012). Notter et al. (2007) used four land-use scenarios and outputs from a GCM to assess the impacts of climate change and land-use change on flood flows. They found that the influence of climate change on floods was greater than that of land-use change, and changes in climate could significantly affect flood peaks and frequencies. The aforementioned studies used various land-use change scenarios, and examined the impacts of land-use change on flood flows. Some of them have investigated the impacts of combined land-use and climate changes on flood flows. Overall, results from these studies follow the theory: flood flows increase when impervious areas increase in a catchment. It is important to plan and develop scenarios carefully as results vary with scenarios.

Assessment of flood risk which is influenced by climate and land-use change has not been carried out in SEQ. It is important to understand changes of climate because they may result in variable rainfall and affect flood risk; land-use is also an important factor in assessing flood risk as it affects surface runoff. Previous research has been mainly focused on the impact of climate change on flood risk. Although there has been some research on how both climate change and land use impact flood risk, this risk has not been assessed in SEQ. The objective of the research is to evaluate the combined impacts of climate and land-use changes on flooding in one semi-rural and one urbanised catchment in SEQ. For this research, outputs from two climate models (i.e. GFDL CM2.1 and CCAM) are used to create rainfall scenarios, and two land-use change scenarios are also developed for impact assessment. A rainfall-runoff model, RORB, is calibrated and validated using historical rainfall and flood 
hydrographs. This calibrated model is then used for predicting flood runoff based on aforementioned scenarios for the two catchments. Details of data and methodology used for this study are described in the next section.

\section{DATA AND METHODOLOGY \\ Study area and the observations}

For the purpose of rainfall-runoff modelling, the selection of a medium catchment size is desirable. In order to assess how land-use change may impact flooding, different land-use types are also required for selecting a study area. Two catchments in the Brisbane region were selected for this study: viz, the Oxley Creek catchment $\left(260 \mathrm{~km}^{2}\right)$ and the Bulimba Creek catchment $\left(128 \mathrm{~km}^{2}\right)$. The mean annual rainfall is approximately $1100 \mathrm{~mm}$ in the Brisbane region. These two creeks are major tributaries of the lower Brisbane River. Both Bulimba and Oxley Creeks flow from south to north into the Brisbane River (Brisbane City Council, 1992). Due to intensive population growth over the past decades, the land-use in the downstream section of the Oxley Creek catchment has changed from rural to urban; however, the upper stream section remains rural (Brisbane River Management Group \& Oxley Creek Catchment Coordinating Committee 1998). The impervious area of the Bulimba Creek catchment has gradually increased over the years due to the construction of roads, footpaths and buildings.

Streamflow and rainfall data were used for the rainfall-runoff modelling for each of the two catchments. Each catchment has two streamflow gauging stations. Further, one gauging station is located at the upstream of the Oxley catchment and the other is located downstream of the catchment. The flow gauging station at the downstream part of the Oxley Creek catchment only had flow data from 1972 to 1974 . The flow data at the flow gauging station located at the upstream of the Oxley Creek catchment were available from 1976 to 1996, and 8 major flood events were recorded during this period. Therefore, flow data from this flow gauging station (ID: 143033A) were used in this study. For the Bulimba Creek catchment, both gauging stations are located upstream of the catchment. One of the gauging stations recorded streamflow data from 1949 to 1971, along with only three flood events in the early 1950s. The flow data were available from the other gauging station from 1971 to 1996, with 12 major flood events being recorded during this period. As such, flow data from this gauging station (ID: 143094A) were used for rainfall-runoff modelling. Daily and six minute rainfall data from the Australian Bureau of Meteorology (BOM) were also used rainfallrunoff simulations. Moreover, the annual maximum rainfall series is used as suggested by Xuereb and Green (2012). The World Meteorological Organization (WMO) suggests that 30 years is a standard period for climate classification and assessment; therefore, rainfall data for 1961-1990 were collated herein and used as the baseline for rainfall-runoff modelling.

The digital land-use map for 1999 was used as the baseline because of data availability, even though it is outside the study period of 1961-1990 (Queensland Department of Natural Resources and Mines, 1999). The impervious fractions were estimated from land-use types and their corresponding impervious fractions in the nearby Norman Creek catchment (Trevithick \& Yu, 2010). Since the flow data at the upper part of the catchments were used, the impervious fractions were estimated only for the upper part of the catchments (upstream from the gauging stations). Based on the 1999 land-use map, the estimated area average imperviousness fraction was 0.05 for the upper part of the Oxley Creek catchment, and most of the area recreational use or reserves. On average, the imperviousness fraction was 0.36 in the upper part of the Bulimba Creek catchment, and most of the remaining catchment consisted of grass, farm and forested lands in the headwater area and along the creek. Figure 1 shows the location of the three catchments, gauging stations and land-use types in 1999. 


\section{The projected future climate and land-use scenarios}

The projected future climate for this research was based on a GCM and a RCM with the IPCC A2 scenario (Nakicenovic et al., 2000). The advantage of using one GCM and one RCM was to provide an acceptable range of future climate change scenarios. The GFDL CM2.1, at a resolution of 2-2.5 deg., was widely used for climate change impact analyses (Tuleya et al., 2007). A higher resolution (i.e. 0.15 deg.) of regional climate model, CCAM, which is a downscaled model from the Australian CSIRO MK 3.0 GCM (Chiew et al., 2010) was also used for comparison purposes. Outputs from these two models were tested and results showed broad agreement with observations for the baseline period of 1961-1990 for SEQ (Kent et al., 2012).

Outputs from these two models were available at a daily time scale for the reference period 1961-1990 and a future period 2016-2045. Results from evaluating the mean annual maximum daily rainfall showed that GFDL CM2.1 and CCAM were respectively $7 \%$ higher and $36 \%$ lower than the observations for the baseline period (Chen et al., 2012). Although CCAM simulated extreme rainfall is not as accurate when compared to observed extreme rainfall, the higher resolution of CCAM makes it favourable for use in this research. As daily output cannot be used directly for sub-daily flood simulations, temporal downscaling methods were needed, for example, as developed by Chen et al. (2011). The normal distribution method from Chen et al. (2011) was tested herein, and it was found that the peak intensities were under-estimated. For example, the peak rainfall intensity from the downscaling is $23.3 \mathrm{~mm} / \mathrm{h}$, but the observed peak rainfall intensity from the pluviograph station 40529 is $50.8 \mathrm{~mm} / \mathrm{h}$. In addition, this pluviograph station is located in the centre of the Bulimba Creek catchment. The downscaling technique was thus excluded from this study, in favour of a new method.

A new method based on historical observations and GCM-predicted daily precipitation was developed for this study. This method is based on the assumption that historical observations may be adjusted to simulate future flood-producing storms as predicted by climate models for the same frequency of occurrence. For a given frequency of occurrence, changes in daily precipitation amounts were calculated as ratios between the two 30-year periods. These ratios, called adjustment factors, were then applied to historical data for the same frequency of occurrence in terms of total rainfall depth. Two methods were used to empirically determine the frequency of occurrence. Method 1 considered all the daily precipitation amounts for the 30 -year period. Method 2 only considered the annual maximum daily rainfall amount. Figure 2 illustrates the rainfall adjustment factors for both methods. As the first method was based on daily rainfall amounts, no rainfall occurred at the higher exceedance probabilities (i.e., >0.8). Also, only extreme rainfall is important for flood studies; therefore, the rainfall adjustment factor for Method 1 is only shown up to 0.1 of exceedance probability (see Figure 2). These rainfall adjustment factors were used in conjunction with land-use scenarios.

Development of future land-use scenarios for hydrological impact analyses is a complex task as it involves the actual urban planning for specific regions and various economic factors. For the purpose of this study, two scenarios were developed following suggestions from Lahmer et al. (2001). The first scenario was a moderate but realistic urban development which was a conversion of all farms to urban land. On average the impervious fraction increased slightly from 0.051 (baseline) to 0.053 (scenario 1) for the upper part of the Oxley Creek catchment. For this scenario, the impervious fraction was increased from 0.36 to 0.39 in the upper part of the Bulimba catchment. The second scenario was the worst case development scenario with a conversion of all the remaining farm and forested lands to urban areas in the catchment, giving average impervious fractions of 0.44 in the Oxley Creek catchment and of 0.48 in the Bulimba Creek catchment. 


\section{Flood modelling}

A commonly used non-linear rainfall-runoff model, RORB, was used to simulate future flood hydrographs. In RORB, a catchment is divided into sub-areas and each is represented by a lumped hydrologic unit (Laurenson et al., 2010). Rainfall excess is estimated with a simple infiltration model consisting of initial loss amount $(I L)$ and constant loss rate $(C L)$ for each sub-area, and the rainfall excess is then routed through the catchment using a storagedischarge relationship to produce runoff hydrographs (Laurenson et al., 2010). For calibration purposes, $I L$ needs to be specified, while $C L$ is calculated automatically based on mass balance. The storage for each sub-area is represented as follows:

$$
S=k Q^{m}
$$

where $S$ is the storage, $k$ is the empirical coefficient, $Q$ is the outflow discharge and $m$ is an exponent. The value for the parameter $\mathrm{m}$ of 0.8 is recommended by the RORB user manual and other studies (Yu 1989, Mazion \& Yen 1994, Laurenson et al. 2010). The coefficient k is decomposed into:

$$
k=k_{c} \times k_{r}
$$

in which $k_{c}$ is the coefficient related to the size of the catchment and $k_{r}$ is a dimensionless ratio related to the delay time for each sub-area, and $k_{r}$ does not require calibration.

Eight and twelve flood events were available for the Oxley and Bulimba Creek catchments respectively to calibrate and validate the RORB model. The first half of the available flood events were used to calibrate the $k_{c}$ and $m$ values, and the second half of the events were used for validation. The calibration was undertaken by giving a set of $m$ values ranging from 0.7 to 0.9 and a fixed initial infiltration amount of $0 \mathrm{~mm}$. The value of $k_{c}$ was then altered to match the observed peak discharge.

For calibration runs, $C L$ was automatically calculated to allow for impervious areas to simulate the effect of urbanisation (Laurenson et al., 2010):

$$
C L_{i}=\left(1-F_{i}\right) \times C L_{p e r v}
$$

where $C L_{\text {perv }}$ is the baseline rate of infiltration for non-urbanised areas and $F_{i}$ is the fraction of the impervious area for the sub-area, $i$. Future infiltration parameters were estimated using the equations below:

$$
\begin{aligned}
& C L_{\text {perv }}=C L_{\text {current }} /\left(1-F_{\text {current, }} \text { area average }\right) \\
& C L_{\text {future }}=\left(1-F_{\text {future }}\right) \times C L_{\text {perv }}
\end{aligned}
$$

where $C L_{\text {perv }}$ is the continuing loss rate $(\mathrm{mm} / \mathrm{h})$ in the previous area, $C L_{\text {current }}$ is the current continuing loss rate $(\mathrm{mm} / \mathrm{h})$ and $F_{\text {current, }}$ area average is the current average imperviousness fraction for the entire area upstream from the gauging station.

For each catchment, recorded flood events were split for the purpose of model validation and of impact prediction. The overall average and seasonal average of the $C L$ values were calculated from the first half of flood events. For the sub-tropical region of SEQ, only two seasons were considered, namely the dry season of May to September, and the wet season of October to April. The second half of flood events was then used for validation purpose, where the calibrated $k_{c}, \mathrm{~m}$ and average $C L$ values were applied. $C L$ is calculated for the whole catchment; therefore, $C L_{p e r v}$ is then calculated based on the average of fraction 
imperviousness for the whole catchment (equation 4 and 5).

\section{RESULTS \\ Calibrate and validation}

Figure 3 illustrates the relationship between $k_{c}$ and $m$. A fixed $m$ value of 0.8 was adopted because the $k_{c}$ values converged approximately to a fixed value when $m$ was close to 0.8 for the calibration events, as similar to what was reported in the literature (Weeks, 1986; Yu 1989; Brisbane City Council 1992; Mazion \& Yen 1994). In order to determine the best $k_{c}$ values for the Oxley and Bulimba Creek catchments, the mean $k_{c}$ values and their standard deviations were calculated at the $m$ value of 0.8 . Four flood events were used for calibration of the Oxley Creek catchment. The mean $k_{c}$ value for the Oxley Creek catchment was 7.73 with a standard deviation of 0.27 . For the Bulimba Creek catchment, the mean $k_{c}$ value was 5.65 with a standard deviation of 0.24 . The overall average $C L$ values for the calibration events were $1.73 \mathrm{~mm} / \mathrm{h}$ for the Oxley Creek and $1.51 \mathrm{~mm} / \mathrm{h}$ for Bulimba Creek catchments. For floods in the wet half of the year (i.e. Nov-Apr), the mean $C L$ values $(1.29 \mathrm{~mm} / \mathrm{h}$ and $1.13 \mathrm{~mm} / \mathrm{h}$ ) were slightly lower than the mean $C L$ values $(2.17 \mathrm{~mm} / \mathrm{h}$ and $1.89 \mathrm{~mm} / \mathrm{h})$ in the dry season (i.e. May-Oct) for both catchments (Oxley and Bulimba).

The aforementioned mean $k_{c}$ and $C L$ values were used for the validation events. Table 1 shows the errors in simulated runoff volumes and peak discharges using $m$ value of 0.8 , mean $k_{c}$ values, and seasonal and overall mean continuing loss rates $(C L)$ for the validation events. In the Oxley Creek catchment, two flood events occurred in the dry season and two flood events in the wet season. The seasonal mean $C L$ and overall average $C L$ values were applied for validation purposes. All the validated events occurred during the wet season (i.e. NovApr) for the Bulimba Creek catchment, the average $C L$ value and the seasonal $C L$ for the wet season were therefore used for validation purposes. The results showed that the seasonal mean $C L$ values fit slightly better than the overall mean $C L$ values for the Oxley Creek catchment. It appeared that using the mean $C L$ value for the wet season would lead to better validation results, especially in terms of the surface runoff volume in the Bulimba Creek catchment. It was decided to use the mean $k_{c}$ values, constant $m$ value of 0.8 , and the mean $C L$ value depending on the season for all simulations of flood hydrographs to assess the effects of climate and land-use changes for the two catchments.

\section{The impact of climate change on flood frequency}

In the aforementioned Section the rainfall-runoff model, RORB, was calibrated and validated using observed flood hydrographs for one rural and one urbanised catchment, for 1961-1990. In this Section the validated model is used to generate flood hydrographs using projected rainfall based on two climate models, GFDL CM2.1 and CCAM, for 2016-2045. Projected daily rainfall for the two contrasting periods are also used to derive adjustment factors for a given frequency of occurrence.

Sample hydrographs using observed rainfall and adjusted rainfall are illustrated in Figure 4. The 1983 flood event was used to show the flood hydrographs in the Oxley Creek catchment. For this event, the rainfall adjustment factors for GFDL CM 2.1 projected rainfall were 1.09 for Method 1 and 1.14 for Method 2, and the respective increases in peak discharge were $9 \%$ and $14 \%$. For the 1983 flood event, the rainfall adjustment factors for CCAM projected rainfall were 1.0 and 0.89 for Method 1 and Method 2, respectively. For the Bulimba Creek catchment, the 1972 flood event was used. For this event, the rainfall adjustment factors for GFDL CM 2.1 were 1.06 for Method 1 and 1.2 for Method 2, and the respective increases in peak discharge were $6 \%$ and $21 \%$. For the same event, the rainfall adjustment factors for CCAM were 0.81 for Method 1 and 0.79 for Method 2, and the respective decreases in peak discharge were $19 \%$ and $28 \%$. 
Changes to peak discharge as a function of return periods using projected precipitations in the two catchments were illustrated in Figure 6. In addition, changes in peak flows are the ratio of Qp in 2016-2045 to Qp 1961-1990 for the same return period. In general, peak discharge would increase in future years for the same return period using outputs from GFDL CM2.1 and the increase is more pronounced for smaller return periods (Fig. 5). Peak discharge would in general decrease in future years using outputs from CCAM, although an increase in peak discharge is noted when the return period is less than about 2 years.

Table 2 shows the mean peak discharge for the baseline and for different scenarios. The difference between Methods 1 and 2 is smaller than that between GFDL CM2.1 and CCAM for the two catchments tested. On average, GFDL suggests a $11 \%$ increase in the mean peak discharge in the Oxley Creek catchment, and a 7-10\% increase in the peak discharge in the Bulimba Creek catchment from 1961-1990 to 2016-2045. CCAM suggests 10-13\% decrease for the Oxley Creek catchment and 7-11\% decrease in the Bulimba Creek catchment for the same two contrasting periods (Table 2). Overall, GFDL CM2.1 suggests an increase in peak discharge, while CCAM suggests a decrease. The difference between the two methods of rainfall adjustment is smaller than that between different climate models.

To summarise, peak discharge increase for both catchments are significant, and this increase is assumed to be associated with relatively small flood events with short return periods. Another finding is that for the period of 2016-2045, peak discharges derived from GFDL CM 2.1 projected rainfall were higher than those from CCAM projected rainfall.

\section{The impact of land-use change on flood frequency}

The effects of land-use change on flood frequency are presented in Figure 6. For the rural Oxley Creek catchment, a moderate land-use change scenario (i.e. scenario 1) shows little impact on the peak flow. This is due to the upper part of the Oxley Creek catchment only exhibiting a small number of farms which could be converted to urban areas. On the other hand, an extreme land-use change (i.e. scenario 2) for this catchment indicated a significant effect on the change in peak flow especially for small flood events. For the urbanised Bulimba Creek catchment, a slight increase in the peak flow is observed for the projected moderate and extreme land-use scenarios. Note that the land-use differences between these scenarios are also not statistically significant.

Overall, Figure 6 shows that changes in the peak flow are greater for shorter return periods and the increase in peak discharge is reduced for larger but rarer flood events. The worst case scenario from this study is a combination of extreme land-use change and GFDL CM2.1 Method 2. The results show a $21 \%$ and $13 \%$ increase on average for the rural and urbanised catchments investigated (see Table 2).

\section{DISCUSSION AND CONCLUSION}

In an attempt to further the understanding of flood risk in SEQ, future land-use and climatic changes were simulated to evaluate flood runoff. Outputs from two climate models and landuse change scenarios were used to assess likely changes to flooding in rural and urban catchments in SEQ. Calibration and validation of the RORB model, involved the use of observed rainfall and runoff data for the available flood events. It was found that fixed parameter values for runoff routing were adequate for both calibration and validation events for the catchments. In contrast, the parameter values for the continuing loss rate are different for different seasons of the year. It was found that two distinct values, one for the dry season and one for the wet, were adequate for simulation purposes.

The validated RORB model was then used to predict future floods as a result of both climate and land-use changes. Outputs from two climate models, GFDL CM 2.1 and CCAM, were used to adjust historical rainfall data to simulate likely changes to rainfall. Results 
showed that the increase in peak discharge for both catchments would not be significant, and noting that, the increase is likely to be associated with relatively small flood events with short return periods. In another words, changes in the peak flow are greater for shorter return periods and this effect is reduced for larger but rarer flood events. For the same frequency of occurrence, peak discharges for 2016-2045, derived from GFDL CM 2.1 projected rainfall, were higher than those from CCAM projected rainfall.

When evaluating the effects of land-use change on flood frequency, the rural Oxley Creek catchment, a moderate land-use change scenario showed little impact on the flood flow. This is due to the upper part of this catchment only exhibiting a small number of farms which could be converted to urban areas. However, for the extreme land-use change scenario, findings showed a dramatic impact on flood peaks, especially for small flood events in the rural catchment tested. When simulating the projected moderate and extreme land-use scenarios for the urbanised Bulimba Creek catchment, only a slight increase in the peak flow was observed. This was due to this catchment already being extensively urbanised.

The worst case scenario from this study is a combination of extreme land-use change and GFDL CM2.1 Method 2, giving a 21\% and 13\% average increase respectively for the rural and urbanised catchments. In conclusion, climatic changes have greater impacts on the magnitude and frequency of floods in SEQ than land-use changes. Therefore, the engineering hydrology practice in SEQ should place a greater emphasize on future climate change and take into consideration climate change-related parameters in the design stage through to operations of hydrological systems.

Acknowledgements The CCAM and GFDL CM2.1 outputs were prepared by the Australian CSIRO.

\section{REFERENCES}

Bathurst, J.C., Birkinshaw, S.J., Cisneros, F., Fallas, J., Iroumé, A., Iturraspe, R., Novillo, M.G., Urciuolo, A., Alvarado, A., Coello, C., Huber, A., Miranda, M., Ramirez, M. \& Sarandón, R. (2011a) Forest impact on floods due to extreme rainfall and snowmelt in four Latin American environments 2: Model analysis, Journal of Hydrology, 400(3-4), 292-304.

Bathurst, J. C., Ewen, J., Parkin, G., O'Connell, P. E. \& Cooper, J. D. (2004) Validation of catchment models for predicting land-use and climate change impacts. 3 . Blind validation for internal and outlet responses. Journal of Hydrology, 287(1-4), 74-94.

Bathurst, J.C., Iroumé, A., Cisneros, F., Fallas, J., Iturraspe, R., Novillo, M.G., Urciuolo, A., Bièvre, B.D., Borges, V.G., Coello, C,. Cisneros, P., Gayoso, J., Miranda, M. \& Ramírez, M. (2011b) Forest impact on floods due to extreme rainfall and snowmelt in four Latin American environments 1: Field data analysis, Journal of Hydrology, 400(3-4), 281-291.

Booij, M.J. (2005) Impact of climate change on river flooding assessed with different spatial model resolutions. Journal of Hydrology, 303(1-4), 176-198.

Brisbane City Council (1992) Bulimba Creek flood study detailed report. Brisbane: Qasco Sureys Pty Ltd.

Brisbane River Management Group \& Oxley Creek Catchment Coordinating Committee (1998) Oxley Creek catchment management plan draft, Brisbane, Mary Maher \& Associates Pty Ltd.

Chang, H. \& Franczyk, J. (2008) Climate change, land-use change, and floods: toward an integrated assessment. Geography Compass, 2(5), 1549-1579.

Charles, S.P., Bari, M.A., Kitsios, A. \& Bates, B.C. (2007) Effect of GCM bias on downscaled precipitation and runoff projections for the Serpentine catchment, Western Australia. International Journal of Climatology, 27(12), 1673-1690. 
Chen, G. F., Qin, D. Y., Ye, R., Guo, Y. X. \& Wang, H. (2011) A new method of rainfall temporal downscaling: a case study on sanmenxia station in the Yellow River Basin. Hydrol. Earth Syst. Sci. Discuss, 8(2), 2323-2344.

Chen, Y., Yu, B. \& Nagayanagi, R. (2012) Changes to flooding potentials in South East Queensland based on GCM outputs and observations. $34^{\text {th }}$ Hydrology and Water Resources Symposium, Engineers Australia, Sydney, Australia, 19-22 November.

Chiew, F. H. S., Kirono, D. G. C., Kent, D. M., Frost, A. J., Charles, S. P., Timbal, B., et al. (2010). Comparison of runoff modelled using rainfall from different downscaling methods for historical and future climates. Journal of Hydrology, 387(1-2), $10-23$.

Chiew, F.H.S. and McMahon, T.A. (2002) Modelling the impacts of climate change on Australian streamflow, Hydrological Processes, 16(6), 1235-1245.

Chow, V. T., Maidment, D. R. \& Mays, L. W. (1988). Applied Hydrology. McGraw-Hill, New York.

Das, T., Dettinger, M.D., Cayan, D.R. and Hidalgo, H.G. (2011) Potential increase in floods in California's Sierra Nevada under future climate projections, Climatic Change, 109 (1), 71-94.

Delworth, T.L., Broccoli, A.J., Rosati, A., et al. (2006) GFDL's CM2 global coupled climate models. Part I: Formulation and simulation characteristics. Journal of Climate, 19(5): 643-674.

Ewen, J. \& Parkin, G. (1996) Validation of catchment models for predicting land-use and climate change impacts. 1. Method. Journal of Hydrology, 175(1-4), 583-594.

Gnanadesikan, A., Dixon, K.W., Griffies, S.M., et al. (2006) GFDL's CM2 global coupled climate models. Part II: The baseline ocean simulation. Journal of Climate, 19(5): 675-697.

Gooda, M. \& Voogt, S. (2012) Climate Change Impact on Water Availability in the South EastQueensland Region. Urban Water Security Research Alliance Technical Report No. 95.

Kay, A.L., Jones, R.G. and Reynard, N.S. (2006) RCM rainfall for UK flood frequency estimation. II. Climate change results. Journal of Hydrology, 318(1-4), 163-172.

Kay, A., Davies, H., Bell, V. and Jones, R. (2009) Comparison of uncertainty sources for climate change impacts: flood frequency in England. Climatic change, 92(1), 41-63.

Kent, D., Cai, W. \& Nguyen, K. (2012) Projections of exceptional climatic events in South East Queensland produced by a dynamical regional circulation model. Urban Water Security Research Alliance Technical Report No. 62.

Lahmer, W., Pfützner, B. \& Becker, A. (2001) Assessment of land use and climate change impacts on the mesoscale. Phys. Chem. Earth Pt. B, 26(7-8), 565-575.

Laurenson, E. M., Mein, R. G. \& Nathan, R. J. (2010) RORB version 6 runoff routing program user manual. Melbourne: Monash University and Sinclair Knight Merz Pty. Ltd.

Leander, R., Buishand, T. A., van den Hurk, B. J. J. M. \& de Wit, M. J. M. (2008) Estimated changes in flood quantiles of the river Meuse from resampling of regional climate model output. Journal of Hydrology, 351(3-4), 331-343.

Mazion, E. \& Yen, B.C. (1994) Computational Discretization Effect on Rainfall-Runoff Simulation, Journal of Water Resources Planning and Management-Asce, vol. 120, no. 5, pp. 715-734.

Nakicenovic, N. et al. (2000) Emissions Scenarios. Cambridge: Inter-Govenmental Panel on Climate Change.

Notter, B., MacMillan, L., Viviroli, D., Weingartner, R. \& Liniger, H. (2007) Impacts of environmental change on water resources in the Mt. Kenya region. Journal of Hydrology, 343(3-4), 266-278.

Nguyen, K. and McGregor, J. (2009) Modelling the Asian summer monsoon using CCAM. Climate Dynamics, 32(2-3), 219-236.

Nguyen, K.C. and McGregor, J.L. (2012) Numerical simulation of current climate conditions for South East Queensland. Urban Water Security Research Alliance Technical Report No. 78.

Perkins, S.E., Pitman, A.J., Holbrook, N.J. and McAneney, J. (2007) Evaluation of the AR4 Climate Models' Simulated Daily Maximum Temperature, Minimum Temperature, and Precipitation over Australia Using Probability Density Functions. Journal of Climate, 20(17), 4356-4376.

Poelmans, L., Rompaey, A.V., Ntegeka, V. \& Willems, P. (2011) 'The relative impact of climate change and urban expansion on peak flows: a case study in central Belgium', Hydrological Processes, 25(18), 2846-2858.

Queensland Department of Natural Resources and Mines (1999) Queensland Landuse 1999. 
Ouellet, C., Saint-Laurent, D. and Normand, F. (2012) Flood events and flood risk assessment in relation to climate and land-use changes: Saint-François River, southern Québec, Canada. Hydrological Sciences Journal, 57(2), 313-325.

Sriwongsitanon, N. \& Taesombat, W. (2011) Effects of land cover on runoff coefficient. Journal of Hydrology, 410(3-4), 226-238.

Tollan, A. (2002) Land-use change and floods: what do we need most, research or management? Water Science and Technology, 45(8), 183-190.

Trevithick, R. \& Yu, B. (2010) Effects of resolution and scale on the accuracy of impervious fraction for urban catchments in Australia. In: Remote Sensing and Hydrology (ed. by C. Neale \& M. Cosh). IAHS Publication, 352, 257-261. IAHS Press, Wallingford, UK.

Tuleya, R. E., DeMaria, M. \& Kuligowski, R. J. (2007). Evaluation of GFDL and simple statistical model rainfall forecasts for US landfalling tropical storms. Weather Forecast, 22(1), 56-70.

Weeks, W. D. (1986) Flood estimation by runoff routing - model applications in Queensland. Transactions of Institution of Engineers, Australia, CE28(2), 159-166.

Xuereb, K. and Green, J. (2012) Defining Independence of Rainfall Events with a Partial Duration Series Approach. In: C.P.P. Ltd (Editor), $34^{\text {th }}$ Hydrology \& Water Resources Symposium. Engineers Australia, Sydney, Australia, 19-22 November.

$\mathrm{Yu}, \mathrm{B}$. (1989) 'Regional relationships for the runoff routing model (RORB), revisited', Transactions of the Institution of Engineers, Australia. Civil engineering, CE31(4), 186-191. 


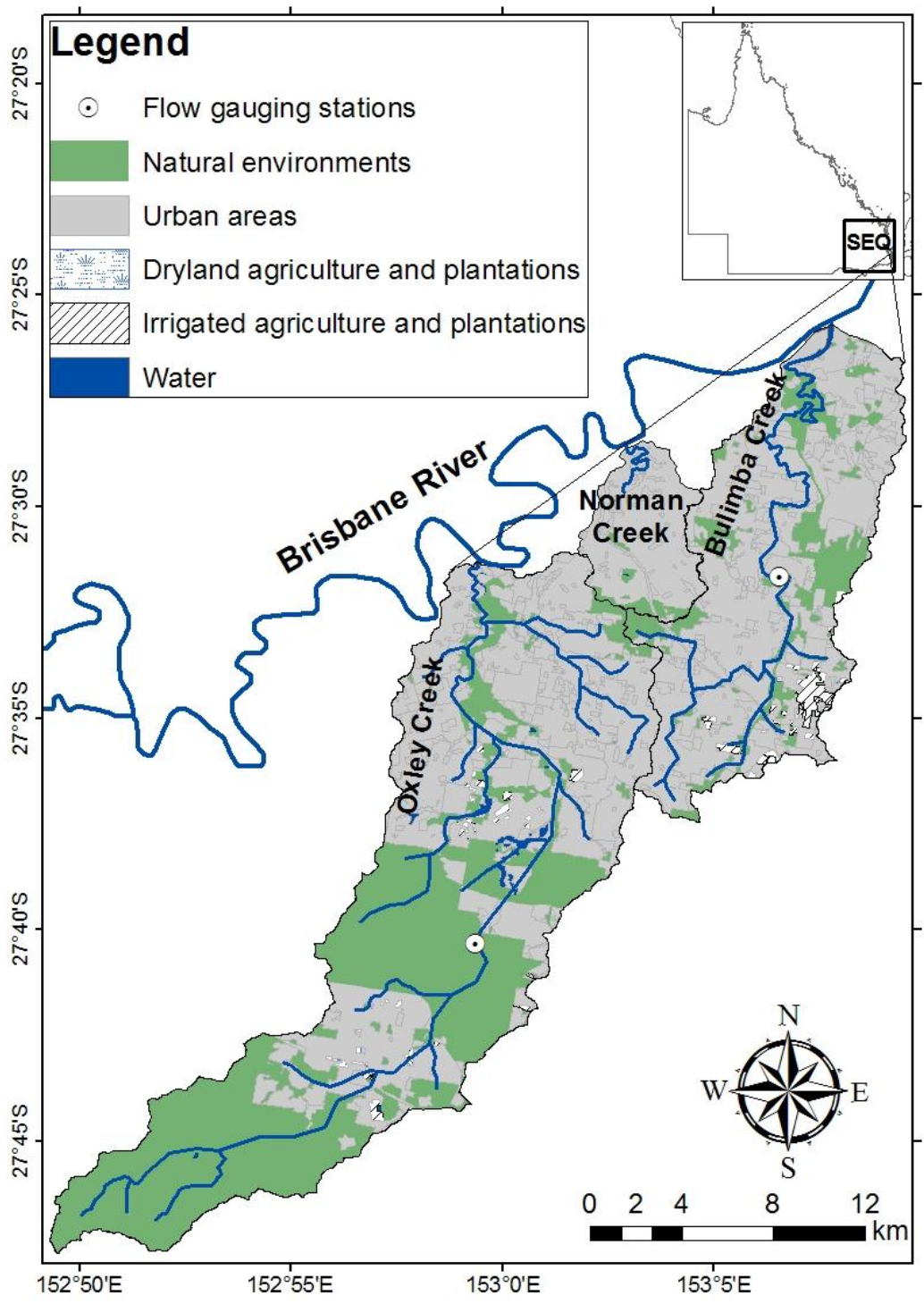

Fig. 1 Details of the study area
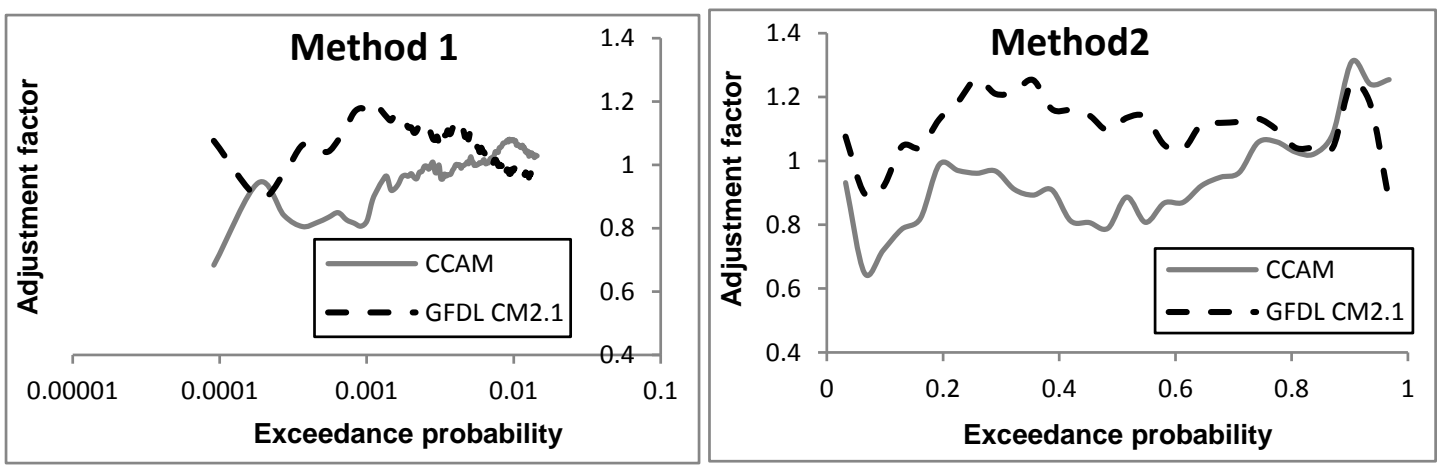

Fig. 2 The adjustment factors using Method 1 and Method 2 

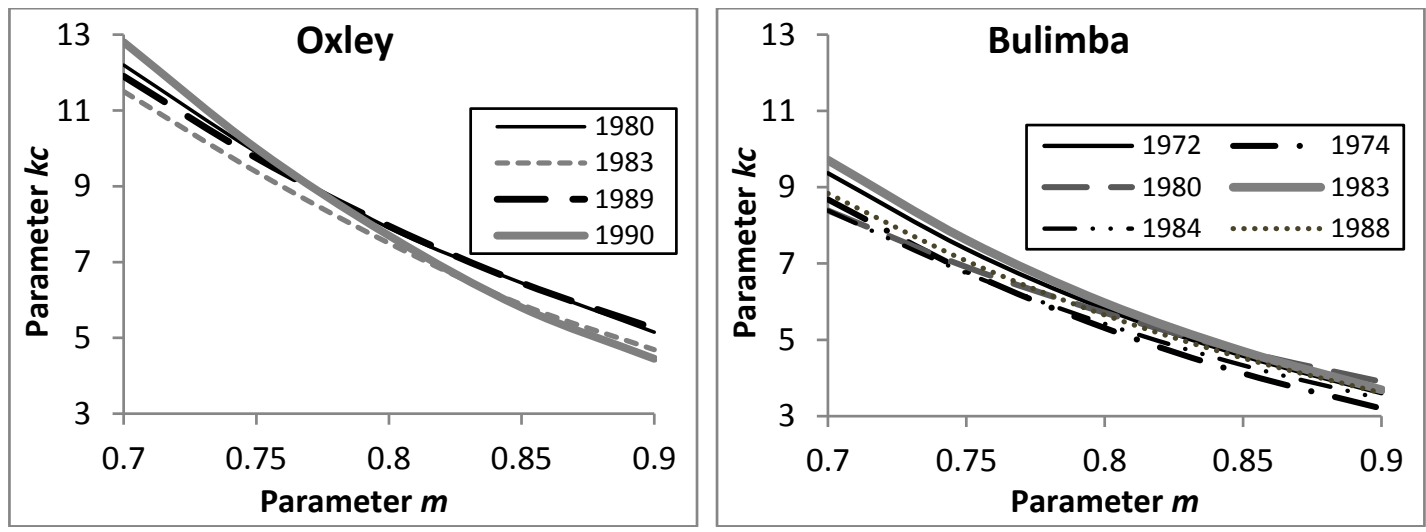

Fig. 3 Relationships between parameters $m$ and $k_{c}$ for selected events
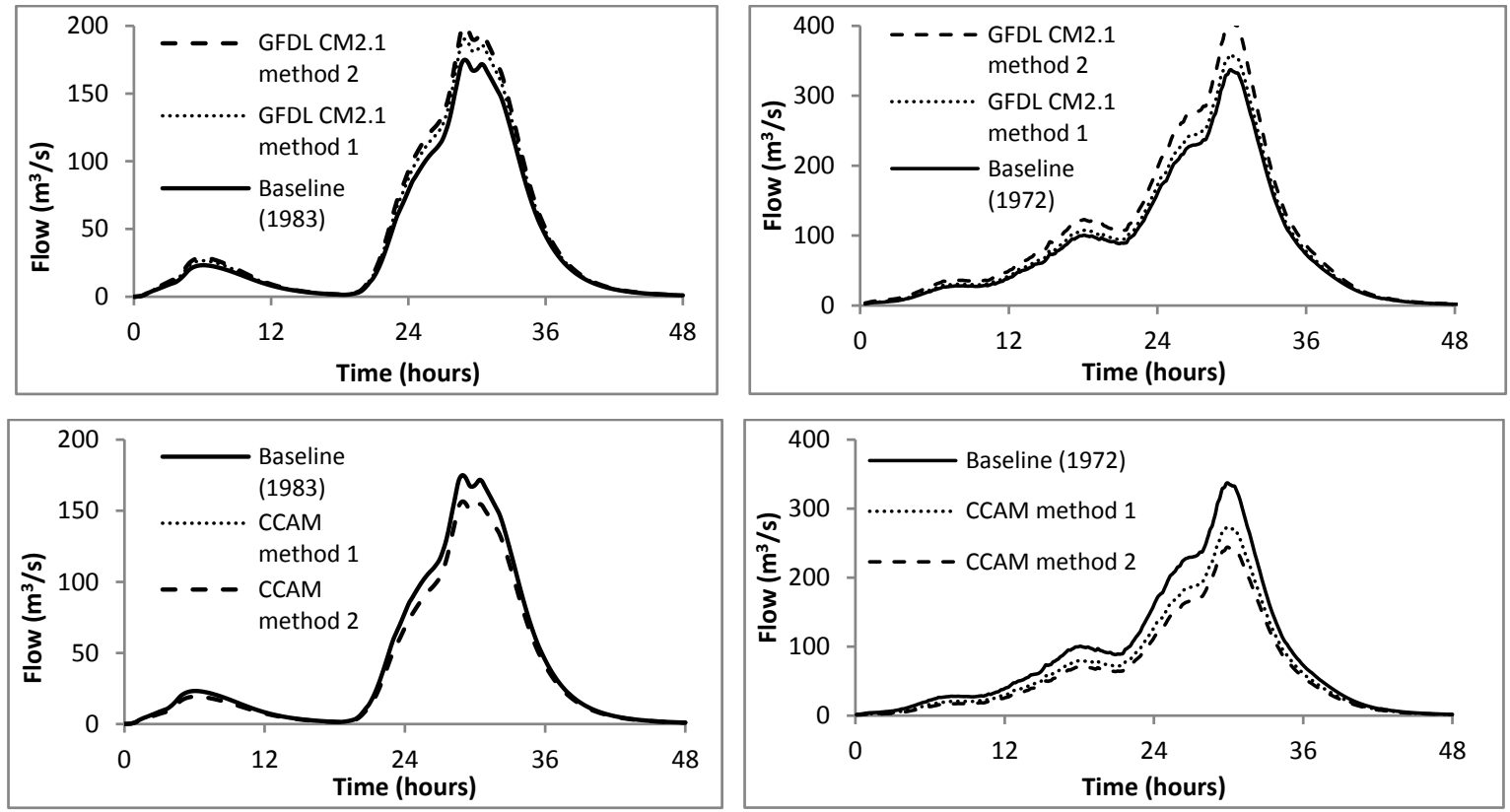

Oxley Creek catchment

Bulimba Creek catchment

Fig. 4 Current and future flood hydrograph derived from observed rainfall (solid line), projected rainfall adjusted by method 1 (dotted line) and method 2 (dashes) 

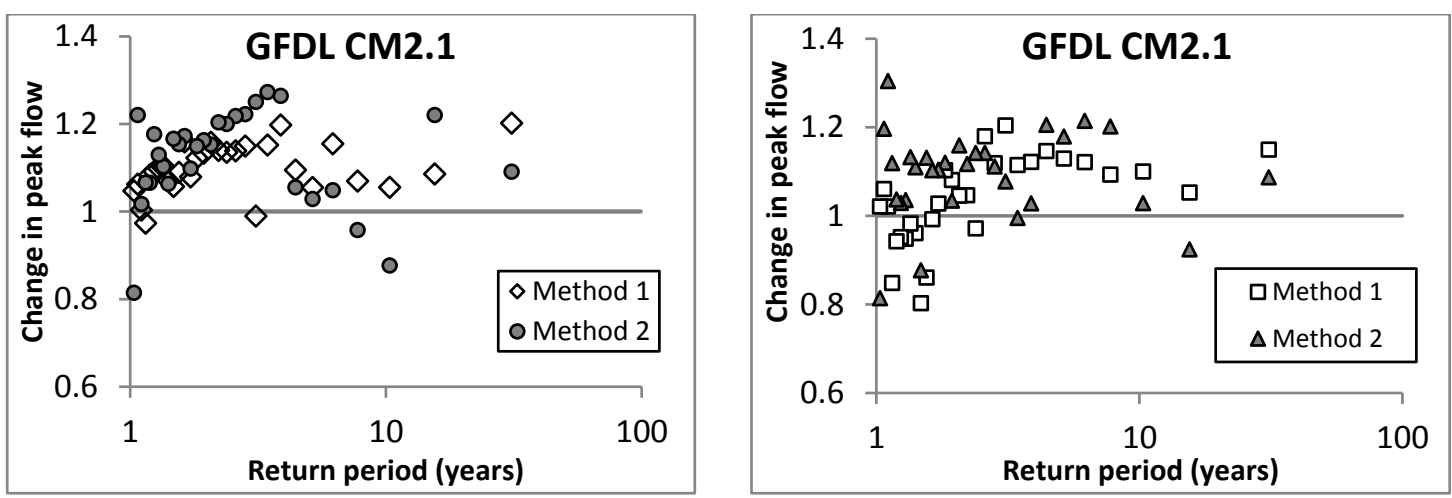

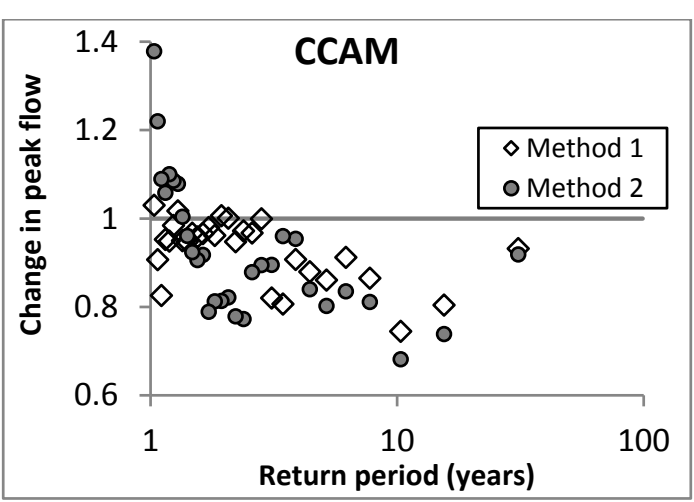

Oxley Creek catchment

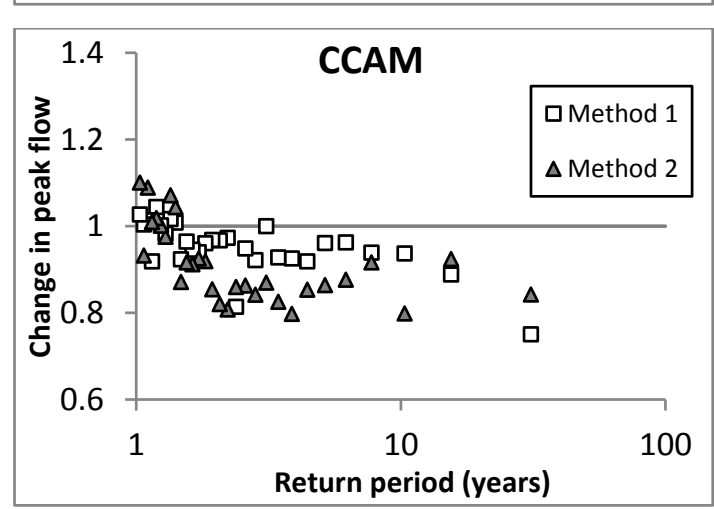

Bulimba Creek catchment

Fig. 5 Changes to peak discharge as a function of return periods using projected rainfall in the two catchments (diamante and circle are for Oxley; square and triangle are for Bulimba).
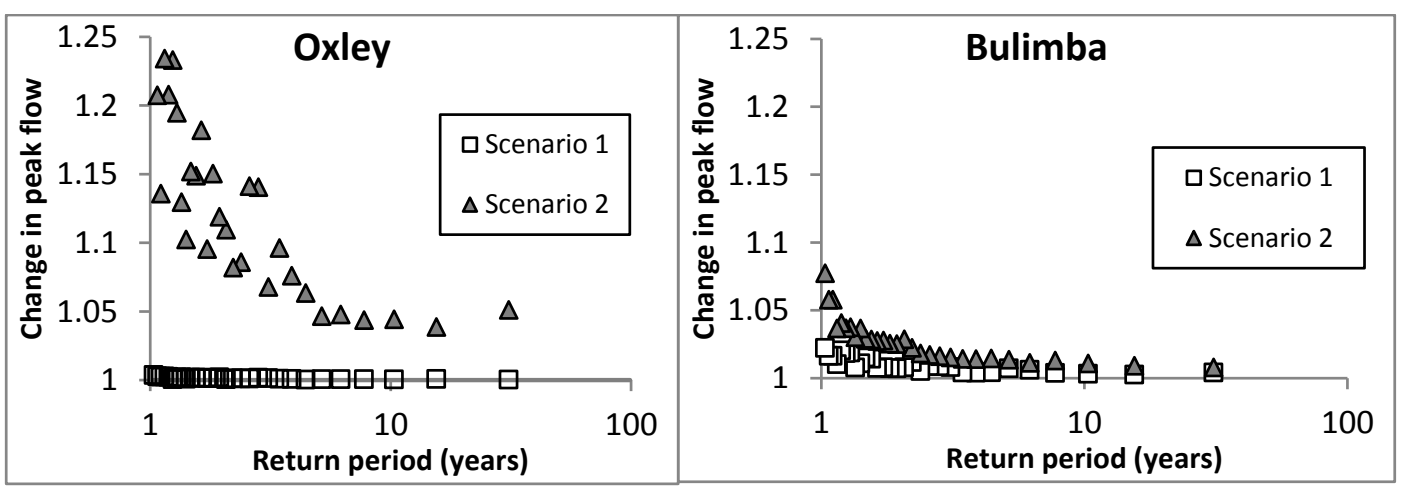

Fig. 6 Changes in peak flows as a function of return periods using two land-use change scenarios. 